\title{
Risk of post-operative cardiovascular event in elderly patients with pre-existing cardiovascular disease who are undergoing hip fracture surgery
}

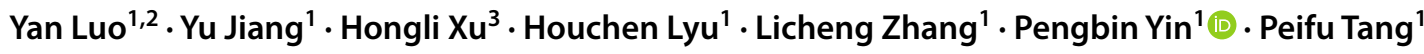

Received: 1 June 2021 / Accepted: 23 September 2021 / Published online: 13 October 2021

(c) The Author(s) 2021

\begin{abstract}
Purpose To evaluate the association between pre-existing cardiovascular disease (CVD) and the risk of developing postoperative cardiovascular event among elderly patients who underwent hip fracture surgery.

Methods We performed an observational study among patients with acute hip fracture aged at least 65 years and who received surgical intervention. Hip fracture patients with pre-existing CVD were matched for age, gender, fracture type, and year of admission with patients without pre-existing CVD. The primary endpoint was post-operative cardiovascular events, and patients were followed until discharge from hospital. Conditional logistic regression was used to determine the association between pre-existing CVD and post-operative cardiovascular event after adjusting for potential confounders including age, body mass index, time from fracture to surgery, pre-existing comorbidities, and the Charlson Comorbidity Index (CCI).

Results The study matched 858 pairs of patients with and without pre-existing CVD. Post-operative cardiovascular events developed in 40 and 14 patients with and without pre-existing CVD (44.6 versus 16.3 per 1000 persons), respectively. Compared to patients without pre-existing CVD, patients with any pre-existing CVD were more likely to develop post-operative cardiovascular events, with a crude odds ratio (OR) of 2.857 [95\% confidence interval (CI), 1.554 to 5.251] and multivariable adjusted OR of 2.850 (95\% CI, 1.318 to 7.139 ), respectively.

Conclusion In elderly patients who received hip fracture surgery, patients with pre-existing CVD are at a higher risk of developing post-operative cardiovascular events. Appropriate screening for this vulnerable population is recommended to prevent the risk of post-operative complications.
\end{abstract}

Keywords Pre-existing cardiovascular disease $\cdot$ Hip fracture $\cdot$ Post-operative cardiovascular events $\cdot$ Elderly

\section{Introduction}

Hip fracture occurs commonly among the elderly [1] with the number of hip fracture cases expected to rise from 1.6 million in 2000 to approximately 6.3 million in 2050 [2]. Most patients with hip fracture need surgical intervention.

Yan Luo and Yu Jiang contributed equally to this work.

Pengbin Yin

yinpengbin@gmail.com

1 Department of Orthopaedics, Chinese PLA General Hospital, Beijing, China

2 National Clinical Research Centre for Orthopaedics, Sports Medicine and Rehabilitation, Beijing, China

3 Medical Big Data Research Centre, Chinese PLA General Hospital, Beijing, China
However, the incidence of post-operative complications in the hip fracture population is disproportionally high due to multiple pre-existing conditions. Post-operative cardiovascular events are frequent $[3,4]$ accounting for around $40 \%$ of all reported complications among patients receiving hip fracture surgery. Identifying patients with the greatest risk of developing post-operative cardiovascular events will help improve preoperative evaluation and inform clinical decision-making in hip fracture surgery.

Previous studies indicate that patients with pre-existing cardiovascular diseases (CVD) such as coronary heart disease, stroke, and heart failure are at a higher risk of developing long-term cardiovascular events. In the general population, patients with a history of CVD are at an increased risk for recurrent vascular events [myocardial infarction (MI), stroke, or vascular death] in a 17-year prospective cohort study [5]. Other researchers have also reported that Chinese 
patients who had any pre-existing MI or stroke were 2.87 times (Hazard ratio, $\mathrm{HR}=2.872,95 \% \mathrm{CI}: 1.503-5.487$ ) more likely to have a subsequent CVD event in 3 years [6]. In another study, for patients who received major surgical operations, peri-operative MI increased the risk of subsequent major adverse cardiac events (MACE) by $70 \%$ in the following year [7]. A study among hip fracture patients reported that patients with pre-existing heart failure had a higher one year post-operative heart failure exacerbation $(\mathrm{HR}=3.00,95 \% \mathrm{CI}: 2.32-3.87)$ and one year mortality $(\mathrm{HR}=2.11,95 \%$ CI: 1.67-2.67) compared to those who did not have underlying or pre-existing heart conditions [8]. Of note, most reported studies have examined the association between pre-existing CVD and the long-term risk of developing cardiovascular events. Few studies have investigated the association between pre-existing CVD and post-operative cardiovascular events, which is a short-term risk following surgical intervention. Most patients with hip fractures are fragile with poor surgical tolerability. Pre-existing CVD combined with acute trauma as well as surgical stress could potentially increase the risk of post-operative cardiovascular events. The quantitative association between pre-existing CVD and post-operative cardiovascular events needs to be determined in this vulnerable population.

The aim of the study was to examine the association between common pre-existing CVD and post-operative cardiovascular events such as MI, stroke, and cardiovascularrelated death among patients with hip fractures who have undergone surgery.

\section{Methods}

\section{Data source and study population}

We used data from the Chinese PLA General Hospital Hip Fracture Study (PLAGH Hip Fracture Study) [9], which is a single-centre cohort study in a tertiary hospital in Beijing, China. The study included all patients who were at least 65 years old with an admission diagnosis of femoral neck or intertrochanteric fracture between January 2000 and April 2016. Hip fractures were considered only if they were occurring for the first time and remedied by surgical intervention. Patients were excluded if they had a second hip fracture or if the fracture was not fresh, indicated by an admission more than three weeks after suffering the fracture.

\section{Study design and cohort definition}

This was an observational cohort study intended to examine the association between pre-existing CVD and the risk of post-operative cardiovascular events among patients who received hip fracture surgery. Each patient with pre-existing
CVD was matched for age ( \pm 3 years), gender, fracture type, and year of admission to a hip fracture patient without preexisting CVD.

Pre-existing CVD was defined as having one of the following diagnosis at admission: coronary heart disease (including MI, silent myocardial ischemia, angina pectoris), cerebrovascular events (including ischemic stroke and haemorrhagic stroke), peripheral artery disease and heart failure, and other cardiovascular diseases (including arrhythmia, valvular heart disease, and pulmonary heart disease) [10]. The diagnosis of the above conditions was undertaken by medical specialists (cardiologist or neurologist) based on patient history and medical records or admission results based on electrocardiogram, coronary computed tomography (CT), echocardiogram, and cranial CT/magnetic resonance imaging (MRI).

\section{Assessment of outcomes}

The primary outcome was a composite endpoint of postoperative cardiovascular events, including post-operative myocardial infarction, stroke, and cardiovascular-related death $[11,12]$. Secondary outcomes were (a) overall cardiovascular system-related events, including post-operative pulmonary embolism, angina pectoris, myocardial infarction, heart failure, arrhythmia, stroke, and cardiovascularrelated death; (b) stroke; and (c) myocardial infarction. All diagnoses were confirmed by medical specialists (cardiologist, neurologist or internists from intensive care unit) based on post-operative lab tests, electrocardiogram, coronary or cranial CT, or MRI.

\section{Assessment of covariates}

Demographic data included age, gender, and body mass index (BMI). The type of hip fracture was classified into either femoral neck fracture or intertrochanteric fracture according to the AO fracture classification [13]. Noted peri- and intra-operative factors include the type of surgical procedure (total hip replacement, semi-hip replacement, intramedullary nailing or other), type of anaesthesia (general anaesthesia, intra-spinal anaesthesia, nerve block and local anaesthesia), time from fracture to surgery, blood loss and transfusion, and operation duration time. Patients' comorbidities were defined based on their medical history. Comorbidities of interest included type 2 diabetes, hypertension, chronic obstructive pulmonary disease (COPD), stroke sequelae (defined as the remaining language, mental, or physical dysfunction after stroke), dementia, and tumour. In addition, pre-existing disease burden was also calculated using the Charlson Comorbidity Index (CCI), which is a significant predictor of complications and both short-term and long-term mortality [14]. The CCI score was summed 
up according to specific weights assigned to each condition [15].

\section{Statistical analysis}

For the comparison of baseline characteristics between patients with and without pre-existing CVD, we used Chi-square or Fisher's exact test for categorical variables, row mean scores difference test for ordinal variables, and Mann-Whitney $U$ test/ t-test for non-normal/normal continuous variables. A simple imputation method using the medium was used for a few missing values in blood loss and surgery time. We calculated the risk of post-operative cardiovascular events in both groups. The conditional logistic regression was used in the 1:1 matched dataset to evaluate the risk of developing post-operative cardiovascular events, adjusting for potential confounders (age, body mass index, time from fracture to surgery and type 2 diabetes, hypertension, COPD, stroke sequelae, dementia, tumour, and the CCI score). In a sensitivity analysis, we repeated the same analysis in the full cohort using unconditional logistic regression. To evaluate whether the pre-existing CVD can serve as a useful clinical characteristic to identify high-risk patients with regard to developing post-operative cardiovascular events, we performed an exploratory analysis by examining the proportion of recurrent cases (patients had a history of this condition) for arrhythmia, stroke, heart failure, and MI. All statistical analyses were performed using the R software (R Foundation, version 3.5.1), and $P<0.05$ was considered statistically significant.

\section{Results}

Of the 3089 patients sampled between the study period, 2106 $(68.2 \%)$ were included in this analysis. The medium age of the included patients was approximately 79.0 (interquartile range, IQR: 10.5 ) years, $67.5 \%$ of them were females, and $48.7 \%$ of them had femoral neck fracture. There were 910 of 2106 (43.2\%) patients who had pre-existing CVD. After performing the (1:1) matching by age, gender, fracture type, and admission year, 858 patients (94.3\%) with pre-existing CVD were matched to 858 patients without pre-existing CVD (Fig. 1). In the matched dataset, patients with pre-existing CVD had a higher burden of comorbidities such as type 2 diabetes (29.1\% vs. $16.9 \%$ ), hypertension ( $65.3 \%$ vs. $39.4 \%$ ), and chronic kidney disease (4.3\% vs. $2.0 \%$ ) when compared to those without pre-existing CVD. The proportion of CCI index over 2 was $41.4 \%$ in patients with pre-existing CVD and $12.7 \%$ in those without pre-existing CVD (Table 1).

For the primary endpoint, post-operative cardiovascular events occurred in nearly thrice as many patients with
Fig. 1 Study population. CVD, cardiovascular disease

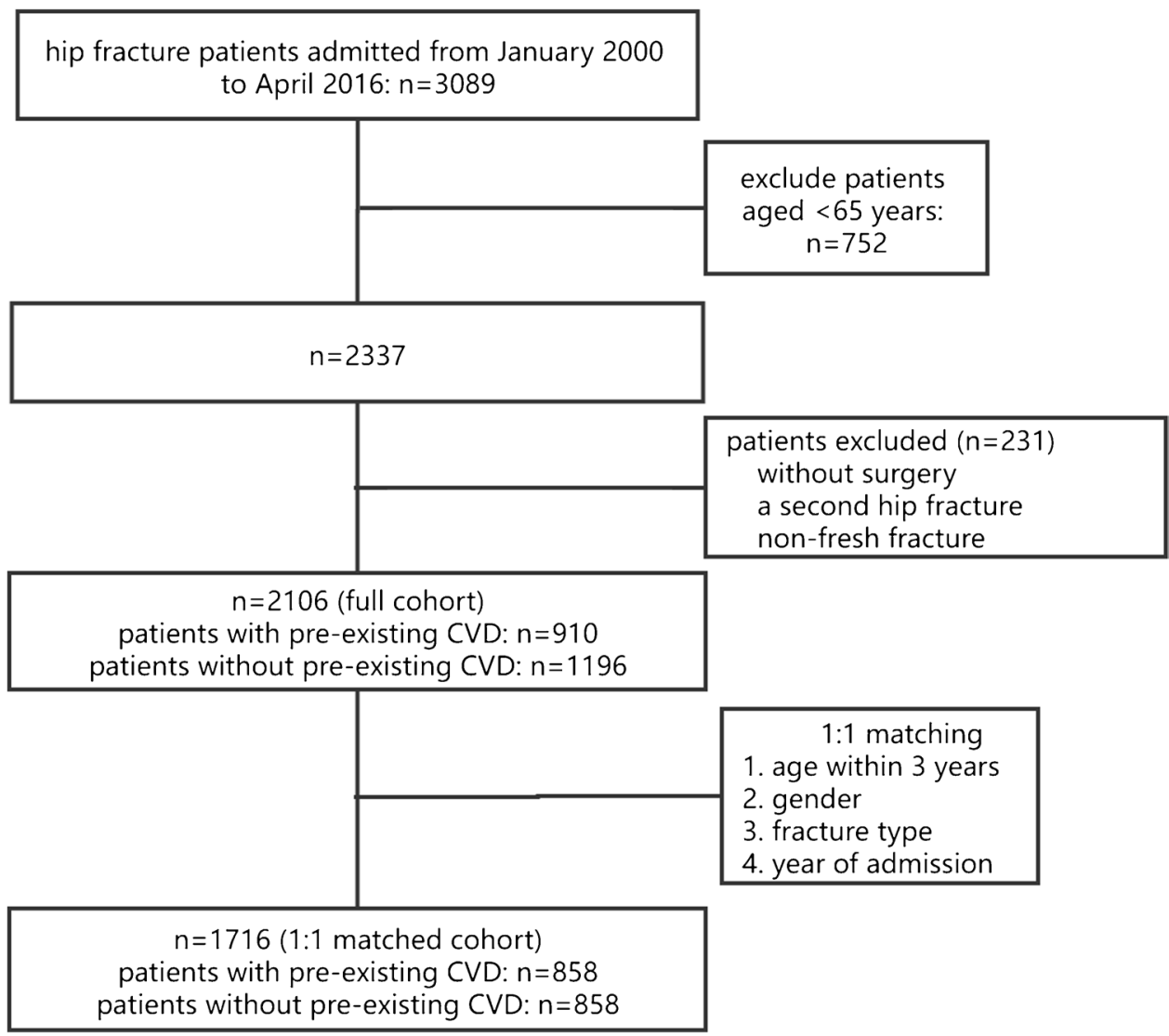


Table 1 Baseline characteristics of the study population in the matched cohort

\begin{tabular}{|c|c|c|c|}
\hline & $\begin{array}{l}\text { Patients without pre-existing } \\
\text { CVD }^{*}(n=858)\end{array}$ & $\begin{array}{l}\text { Patients with pre-existing CVD } \\
(n=858)\end{array}$ & $P$ \\
\hline$n$ & 858 & 858 & \\
\hline Age (median [IQR]) & $79.06[74.12,84.12]$ & $79.37[74.62,83.85]$ & 0.849 \\
\hline BMI (median [IQR]) & $22.49[19.78,24.44]$ & $22.66[20.76,25.09]$ & $<0.001$ \\
\hline Gender $(\%)$ & & & 1.000 \\
\hline Male $(\%)$ & $289(33.7)$ & $289(33.7)$ & \\
\hline Female (\%) & $569(66.3)$ & $569(66.3)$ & \\
\hline Fracture type (\%) & & & 1.000 \\
\hline Intertrochanteric fracture $(\%)$ & $434(50.6)$ & $434(50.6)$ & \\
\hline Femoral neck fracture $(\%)$ & $424(49.4)$ & $424(49.4)$ & \\
\hline Surgery type (\%) & & & 0.410 \\
\hline Total hip replacement & $70(8.2)$ & $57(6.6)$ & \\
\hline Semi-hip replacement & $372(43.4)$ & $391(45.6)$ & \\
\hline Intramedullary nailing & $405(47.2)$ & $394(45.9)$ & \\
\hline Other $^{\#}$ & $11(1.3)$ & $16(1.9)$ & \\
\hline Anaesthesia (\%) & & & 0.243 \\
\hline General anaesthesia & $285(33.2)$ & $258(30.1)$ & \\
\hline Intra-spinal anaesthesia & $287(33.4)$ & $276(32.2)$ & \\
\hline Nerve block & $278(32.4)$ & $317(36.9)$ & \\
\hline Local anaesthesia & $8(0.9)$ & $7(0.8)$ & \\
\hline Time from fracture to surgery (day) (median [IQR]) & $6.00[4.00,10.00]$ & $7.00[4.00,11.25]$ & $<0.001$ \\
\hline Blood loss in surgery $(\mathrm{mL})$ (median [IQR]) & $200.00[100.00,300.00]$ & $200.00[100.00,300.00]$ & 0.714 \\
\hline Surgery time (min) (median [IQR]) & $105.00[84.50,133.50]$ & $105.00[85.00,135.00]$ & 0.526 \\
\hline Blood transfusion $(\%)$ & $214(27.8 \%)$ & $232(29.5 \%)$ & 0.486 \\
\hline \multicolumn{4}{|l|}{ Comorbidities } \\
\hline Type 2 diabetes (\%) & $145(16.9)$ & $250(29.1)$ & $<0.001$ \\
\hline Hypertension (\%) & $338(39.4)$ & $560(65.3)$ & $<0.001$ \\
\hline Myocardial Infraction (\%) & - & $95(11.1)$ & - \\
\hline Coronary heart disease $(\%)$ & - & $413(48.1)$ & - \\
\hline Arrhythmia (\%) & - & $225(26.2)$ & - \\
\hline Heart failure $(\%)$ & - & $26(3.0)$ & - \\
\hline Stroke $(\%)$ & - & $389(42.7)$ & - \\
\hline Stroke sequelae $(\%)$ & - & $97(10.7)$ & - \\
\hline COPD $(\%)$ & $53(6.2)$ & $63(7.3)$ & 0.387 \\
\hline Pneumonia within 3 months (\%) & $21(2.4)$ & $31(3.6)$ & 0.205 \\
\hline Dementia $(\%)$ & $48(5.6)$ & $42(4.9)$ & 0.588 \\
\hline Tumour (\%) & $63(7.3)$ & $71(8.3)$ & 0.529 \\
\hline Malignant tumour (\%) & $39(4.5)$ & $49(5.7)$ & 0.325 \\
\hline Rheumatic disease (\%) & $13(1.5)$ & $19(2.2)$ & 0.372 \\
\hline CKD $(\%)$ & $17(2.0)$ & $37(4.3)$ & 0.009 \\
\hline Peptic ulcer disease (\%) & $63(7.3)$ & $80(9.3)$ & 0.162 \\
\hline Liver disease $(\%)$ & $15(1.7)$ & $21(2.4)$ & 0.400 \\
\hline $\mathrm{CCI}(\%)$ & & & $<0.001$ \\
\hline 0 & $535(62.4)$ & $196(22.8)$ & \\
\hline 1 & $214(24.9)$ & $307(35.8)$ & \\
\hline $1+$ & $109(12.7)$ & $355(41.4)$ & \\
\hline Pre-operative haemoglobin, $\mathrm{Hb}$ (g/L) (mean (SD)) & $38.78(4.28)$ & $38.97(4.38)$ & 0.383 \\
\hline Post-operative haemoglobin, $\mathrm{Hb}(\mathrm{g} / \mathrm{L})$ (mean (SD)) & $32.45(3.93)$ & $32.87(4.36)$ & 0.046 \\
\hline Pre-operative serum creatinine, $\mathrm{Cr}$ (umol/L) (mean (SD)) & $75.43(55.40)$ & $79.04(55.05)$ & 0.178 \\
\hline Post-operative serum creatinine, $\mathrm{Cr}$ (umol/L) (mean (SD)) & $71.88(57.85)$ & $75.36(54.80)$ & 0.208 \\
\hline
\end{tabular}


Table 1 (continued)

\begin{tabular}{|c|c|c|c|}
\hline & $\begin{array}{l}\text { Patients without pre-existing } \\
\text { CVD }^{*}(n=858)\end{array}$ & $\begin{array}{l}\text { Patients with pre-existing CVD } \\
(n=858)\end{array}$ & $P$ \\
\hline Pre-operative serum calcium, $\mathrm{Ca}(\mathrm{mmol} / \mathrm{L})($ mean $(\mathrm{SD}))$ & $2.24(0.15)$ & $2.25(0.14)$ & 0.200 \\
\hline Post-operative serum calcium, $\mathrm{Ca}(\mathrm{mmol} / \mathrm{L})($ mean $(\mathrm{SD}))$ & $2.13(0.15)$ & $2.15(0.16)$ & 0.056 \\
\hline Pre-operative serum albumin, Alb (g/L) (mean (SD)) & $38.78(4.28)$ & $38.97(4.38)$ & 0.383 \\
\hline Post-operative serum albumin, $\mathrm{Alb}(\mathrm{g} / \mathrm{L})$ (mean (SD)) & $32.45(3.93)$ & $32.87(4.36)$ & 0.046 \\
\hline Pre-operative C-reactive protein, $\mathrm{CRP}(\mathrm{mg} / \mathrm{dL})$ (mean (SD)) & $6.07(5.65)$ & $6.13(6.11)$ & 0.862 \\
\hline Post-operative C-reactive protein, CRP (mg/dL) (mean (SD)) & $5.67(4.23)$ & $5.38(4.15)$ & 0.195 \\
\hline Pre-operative D-dimer $(\mu \mathrm{g} / \mathrm{mL})($ mean $(\mathrm{SD}))$ & $6.86(6.06)$ & $7.13(5.94)$ & 0.377 \\
\hline Post-operative D-dimer $(\mu \mathrm{g} / \mathrm{mL})($ mean (SD)) & $5.18(4.67)$ & $4.48(4.58)$ & 0.021 \\
\hline
\end{tabular}

$C V D$, cardiovascular disease; $I Q R$, interquartile range; $B M I$, body mass index; $C O P D$, chronic obstructive pulmonary disease; $C K D$, chronic kidney disease; $C C I$, Charlson Comorbidity Index

*Pre-existing CVD: we defined a history of pre-existing CVD as having one of the following conditions: coronary heart disease (including myocardial infarction, silent myocardial ischemia, angina pectoris), cerebrovascular events (including ischemic stroke and haemorrhagic stroke), heart failure, and other cardiovascular diseases (including arrhythmia, valvular heart disease, and pulmonary heart disease)

\# Other surgery types including extramedullary fixation, plate, external fixator, and simple fixation

pre-existing CVD (40) as those without underlying CVD (14). Compared to patients without pre-existing CVD, the crude OR of developing post-operative cardiovascular events in patients with pre-existing CVD was 2.857 (95\% CI: 1.554-5.251). After adjusting for potential confounders, the multivariable-adjusted OR was 2.850 (95\% CI: 1.138-7.139). Similarly, for the secondary endpoints, there was a higher risk of developing overall cardiovascular system-related events among patients with pre-existing CVD (107) with a risk of 124.7 (95\% CI, 102.6 to 146.8 ) per
1000 persons compared to those without previous CVD (Table 2).

We performed the same analysis in the full cohort as a sensitivity evaluation. The results were consistent with the primary analysis for both the primary endpoint and three secondary endpoints. For example, compared to patients without pre-existing CVD, the crude and multivariable-adjusted OR for post-operative cardiovascular events were 3.440 (95\% CI: 1.985-6.234) and 3.367 (95\% CI: 1.783-6.566), respectively (Table 3 ).

Table 2 Risk of post-operative CVD events in patients with and without pre-existing CVD in the matched cohort

\begin{tabular}{|c|c|c|c|c|c|c|c|c|}
\hline & \multicolumn{3}{|c|}{ Patients with pre-existing CVD } & \multicolumn{3}{|c|}{ Patients without pre-existing CVD } & \multirow{2}{*}{$\begin{array}{l}\text { Crude } O R(95 \% \\
C I)\end{array}$} & \multirow{2}{*}{$\begin{array}{l}\text { Adjusted } O R(95 \% \\
C I)^{\mathrm{a}}\end{array}$} \\
\hline & $n$ & No. of events & $\begin{array}{l}\text { Risk per } 1000 \\
\text { persons }\end{array}$ & $n$ & No. of events & $\begin{array}{l}\text { Risk per } 1000 \\
\text { persons }\end{array}$ & & \\
\hline \multicolumn{9}{|l|}{ Primary endpoint } \\
\hline $\begin{array}{l}\text { Post-operative } \\
\text { cardiovascular } \\
\text { events }\end{array}$ & 858 & 40 & $46.6(33.5-62.9)$ & 858 & 14 & $16.3(8.9-27.2)$ & $\begin{array}{l}2.857(1.554- \\
5.251)\end{array}$ & $2.850(1.138-7.139)$ \\
\hline \multicolumn{9}{|l|}{ Secondary endpoints } \\
\hline $\begin{array}{l}\text { Overall car- } \\
\text { diovascular } \\
\text { system-related } \\
\text { events }\end{array}$ & 858 & 107 & $\begin{array}{l}124.7(102.6- \\
146.8)\end{array}$ & 858 & 30 & $35.0(23.7-49.5)$ & $\begin{array}{l}3.750(2.472- \\
5.690)\end{array}$ & $3.679(2.115-6.399)$ \\
\hline Stroke & 858 & 32 & $37.3(25.6-52.2)$ & 858 & 8 & $9.3(4.0-18.3)$ & $\begin{array}{l}4.000(1.843- \\
8.680)\end{array}$ & $5.618(1.386-19.271)$ \\
\hline $\begin{array}{l}\text { Myocardial } \\
\text { Infraction }\end{array}$ & 858 & 6 & $7.0(1.4-12.6)$ & 858 & 4 & $4.7(1.3-11.9)$ & $\begin{array}{l}1.500(0.423- \\
5.315)\end{array}$ & - \\
\hline
\end{tabular}

$C V D$, cardiovascular diseases; $O R$, odds ratio; $C I$, confidence interval

*Post-operative cardiovascular events, including post-operative myocardial infarction, stroke, and cardiovascular-related death

\#Overall cardiovascular system-related events, including post-operative pulmonary embolism, angina pectoris, myocardial infarction, heart failure, arrhythmia, stroke and cardiovascular-related death

aAdjusted factors: age, body mass index, time from fracture to surgery, and comorbidities including type 2 diabetes, hypertension, chronic obstructive pulmonary disease, stroke sequelae, dementia, tumour, and the Charlson Comorbidity Index 
Table 3 Sensitivity analysis for the risk of post-operative complications in patients with and without pre-existing CVD in the full cohort

\begin{tabular}{|c|c|c|c|c|c|c|c|c|}
\hline & \multicolumn{3}{|c|}{ Patients with pre-existing CVD } & \multicolumn{3}{|c|}{ Patients without pre-existing CVD } & \multirow{2}{*}{$\begin{array}{l}\text { Crude } O R(95 \% \\
C I)\end{array}$} & \multirow{2}{*}{$\begin{array}{l}\text { Adjusted } O R \\
(95 \% C I)^{\mathrm{a}}\end{array}$} \\
\hline & $n$ & No. of events & $\begin{array}{l}\text { Risk per } 1000 \\
\text { persons }\end{array}$ & $n$ & No. of events & $\begin{array}{l}\text { Risk per } 1000 \\
\text { persons }\end{array}$ & & \\
\hline \multicolumn{9}{|l|}{ Primary endpoint } \\
\hline $\begin{array}{l}\text { Post-operative } \\
\text { cardiovascular } \\
\text { events * }\end{array}$ & 910 & 43 & $47.3(34.4-63.1)$ & 1196 & 17 & $14.2(8.3-22.7)$ & $3.440(1.985-6.234)$ & $3.367(1.783-6.566)$ \\
\hline \multicolumn{9}{|l|}{ Secondary endpoints } \\
\hline $\begin{array}{l}\text { Overall car- } \\
\text { diovascular } \\
\text { system-related } \\
\text { events }\end{array}$ & 910 & 113 & $\begin{array}{l}124.2(102.7- \\
145.6)\end{array}$ & 1196 & 45 & $37.6(27.6-50.0)$ & $3.626(2.556-5.229)$ & $3.909(2.613-5.920)$ \\
\hline Stroke & 910 & 34 & $37.4(26.0-51.8)$ & 1196 & 11 & $9.2(4.6-16.4)$ & $4.181(2.176-8.691)$ & $3.515(1.657-7.920)$ \\
\hline $\begin{array}{r}\text { Myocardial } \\
\text { Infraction }\end{array}$ & 910 & 7 & $7.7(3.1-15.8)$ & 1196 & 4 & $3.3(0.9-8.5)$ & $2.310(0.695-8.842)$ & $2.917(0.721-12.730)$ \\
\hline
\end{tabular}

$C V D$, cardiovascular diseases; $O R$, odds ratio; $C I$, confidence interval

*Post-operative cardiovascular events, including post-operative myocardial infarction, stroke, and cardiovascular-related death

\#Overall cardiovascular system-related events, including post-operative pulmonary embolism, angina pectoris, myocardial infarction, heart failure, arrhythmia, stroke, and cardiovascular-related death

${ }^{a}$ Adjusted factors: age, gender, fracture type, year of admission, time from fracture to surgery, body mass index, and comorbidities including type 2 diabetes, hypertension, chronic obstructive pulmonary disease, stroke sequelae, dementia, tumour, and the Charlson Comorbidity Index

Fig. 2 (A) Recurrent cases of post-operative arrhythmia, stroke, heart failure, and myocardial infarction. (B) Cases of pre-existing cardiovascular disease (CVD)
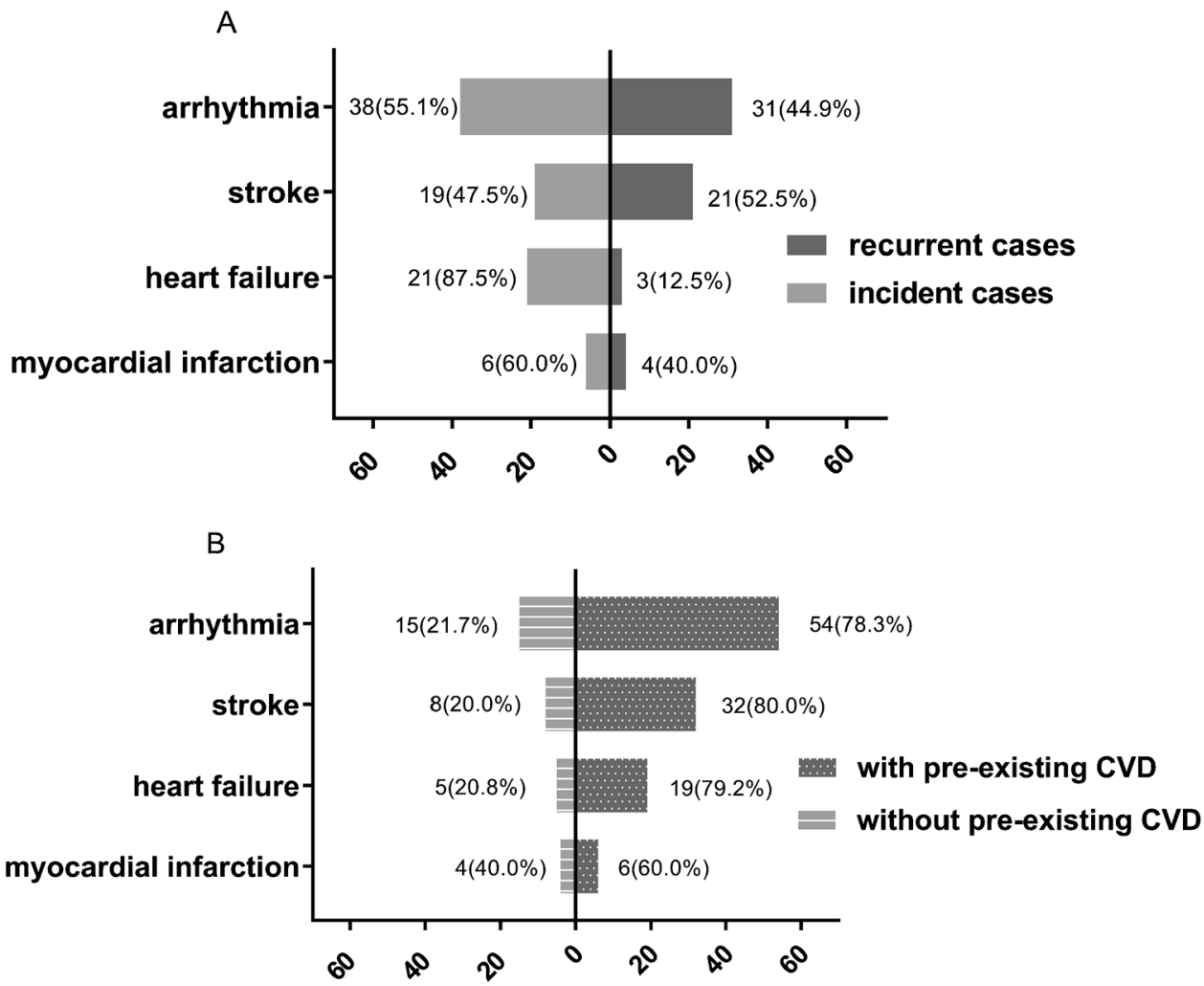
In an exploratory analysis, we examined the proportion of recurrent cases and new cases for post-operative arrhythmia, stroke, heart failure, and MI (Fig. 2). In the primary dataset of the 69 post-operative arrhythmia events, 31 (44.9\%) of them had a history of arrhythmia (Fig. 2A), but 54 (78.3\%) of them had a history of any pre-existing CVD as defined for this study (Fig. 2B). Of the 40 stroke events, 21 (52.5\%) of them had a history of stroke, but $32(80.0 \%)$ had a history of any pre-existing CVD. Of the 24 post-operative heart failure events, three $(12.5 \%)$ had a history of heart failure, while $19(79.2 \%)$ had a history of any pre-existing CVD. Similar results were found for post-operative MI (Fig. 2).

\section{Discussion}

In this study, we examined the association between preexisting CVD and the risk of developing post-operative cardiovascular events in geriatric patients receiving hip fracture surgery. Patients with pre-existing CVD showed an increased risk of post-operative cardiovascular events, including MI, stroke, and cardiovascular-related death, compared to patients without pre-existing CVD.

To the best of our knowledge, this is the first study to examine the association between pre-existing CVD and short-term post-operative cardiovascular events, among patients who have received hip fracture surgery. Such patients who have pre-existing CVD were 2.85 times more likely to develop post-operative cardiovascular events following hip fracture surgery. This result highlights that patients with pre-existing CVD are a vulnerable subgroup with a heightened risk of developing post-operative cardiovascular events.

In a previous study, Jorgensen and colleagues reported that patients with pre-existing stroke have an increased risk of major adverse cardiac events following elective noncardiac surgery. In that study, the 30-day crude incidence of major adverse cardiac events following elective noncardiac surgery was over ten times higher in patients with pre-existing stroke. Furthermore, patients with pre-existing stroke were four times more likely to develop post-operative major adverse cardiac events [16]. In patients receiving joint replacement surgery, a study using national inpatients sample (USA) showed that the history of cardiac diseases is a risk factor for acute myocardial infarction following surgery, with an OR of 4.9 for pre-existing coronary artery disease, 2.6 for congestive heart failure, and 1.2 for valvular disease [17].

Compared to patients receiving elective surgery, patients with hip fracture are more fragile and less tolerant to surgical stress. In view of the high incidence of postoperative cardiovascular events in hip fracture patients, identifying useful risk factors will help physicians find the most vulnerable subgroup of patients. In this study, we showed that pre-existing CVD is a strong risk factor for developing post-operative cardiovascular events.

The current study further evaluated whether pre-existing CVD could serve as a useful clinical characteristic to identify high-risk patients for developing post-operative cardiovascular events. Among patients who experienced post-operative cardiovascular events including MI, stroke, and cardiovascular-related death, the proportion of patients having pre-existing CVD is as high as $80 \%$. For each specific post-operative cardiovascular event (MI, stroke, arrhythmia, and heart failure), most patients had at least one pre-existing CVD. Considering patients who developed MI, $60 \%$ of them had pre-existing CVD. For the other three specific categories, the proportions were even higher (Fig. 2B). By contrast, only half of these are recurrent cases for each specific event (Fig. 2A). This observation suggests that any type of pre-existing CVD is a strong risk factor for post-operative cardiovascular event and could possibly be useful in identifying patients at high risk of developing post-operative cardiovascular event.

This study not only highlights the fact that patients who have fractured hips with pre-existing CVD have increased risk of post-operative cardiovascular events, but also provides some quantitative aspects of the risks. The outcomes of this study promise to be useful to clinicians in providing insights during pre-operative evaluation of elderly patients with hip fractures who have CVD comorbidities.

Currently, there is no routine post-operative CVD events surveillance framework. Framingham Risk Score (FRS) [18] and Atherosclerotic Cardiovascular Disease (ASCVD) [19] risk assessment tools are useful risk scoring systems in predicting CVD risk among non-hip fracture populations. Therefore, the validity and usefulness of applying these scores in predicting post-operative cardiovascular events among patients with hip fractures are unclear. Expanding these predictive models to cater for patients with hip fractures by incorporating some population-specific risk factors is an unmet need. Recently, some potentially useful risk factors or biomarkers of post-surgical complications have been proposed by several studies. These risk factors include old age, poor physical status, and receiving pre-operative red blood cell transfusions frequently [1]. In addition, some biomarkers, such as levels of brain natriuretic peptide (NT-proBNP) [20, 21], troponin I [22, 23], and haemoglobin [24], have demonstrated their potential for assessing the risk of the occurrence of CVD events after surgery. In this study, we found that one or a combination of pre-existing CVD can serve as a simple and yet effective marker to identify patients vulnerable to post-operative cardiovascular events. Based on the study results, pre-existing CVD should be incorporated in 
models for predicting post-operative cardiovascular events in patients with hip fractures who go through hip surgery.

This study has some strengths. First, we used data from a large hip fracture cohort. Second, pre-existing CVD and post-operative cardiovascular events were well adjudicated. All these CVD-related diagnoses were made by specialists based on necessary lab tests, electrocardiogram, echocardiogram, and coronary CT/MRI. Third, we used robust study design to examine the association between pre-existing CVD and post-operative cardiovascular events in hip fracture patients. This analysis filled in the knowledge gap over the short-term risk of cardiovascular events after surgery and could be useful for decision marking. Meanwhile, this study has some limitations. Although a large study population was included, this study is a single-centre study. In the 1:1 matching process, $52(5.7 \%)$ patients with pre-existing CVD were not matched with controls since we used strict matching criteria, which may lead to potential biases. However, a sensitivity analysis using all patients with pre-existing CVD did not change our estimates substantially.

\section{Conclusions}

In elderly patients who have undergone hip fracture surgery, pre-existing CVD was a great risk factor for developing postoperative cardiovascular events. Nearly $80 \%$ of patients who experienced post-operative cardiovascular events had at least one pre-existing CVD. Appropriate screening strategies are needed for this vulnerable population to reduce the incidences of post-operative CVD-related complications.

Supplementary Information The online version contains supplementary material available at https://doi.org/10.1007/s00264-021-05227-7.

Author contribution All authors contributed to the study conception and design. Data extraction and assessment were performed by Hongli $\mathrm{Xu}$, Pengbin Yin, Houchen Lyu, and Yu Jiang. Research coordination was done by Licheng Zhang and Peifu Tang. The first draft of the manuscript was written by Yan Luo, Pengbin Yin, and Houchen Lyu. All authors approved the final version of the manuscript.

Funding We acknowledge the support of the National Key Research and Development Program of China (grant number: 2019YFC0840705) and staff in Medical Big Data Research Centre for their super work.

Data and material availability The datasets used or analysed during the current study are available from the corresponding author on reasonable request.

\section{Declarations}

Ethics approval The study was approved by the institutional ethical committee, and the authors certify that the study was performed in accordance with the 1964 Helsinki Declaration and its later amendments or comparable ethical standards.

Consent to participate Not applicable.

Consent for publication All authors have seen the manuscript and approved it to submit to your journal.

Conflict of interest The authors declare no competing interests.

Open Access This article is licensed under a Creative Commons Attribution 4.0 International License, which permits use, sharing, adaptation, distribution and reproduction in any medium or format, as long as you give appropriate credit to the original author(s) and the source, provide a link to the Creative Commons licence, and indicate if changes were made. The images or other third party material in this article are included in the article's Creative Commons licence, unless indicated otherwise in a credit line to the material. If material is not included in the article's Creative Commons licence and your intended use is not permitted by statutory regulation or exceeds the permitted use, you will need to obtain permission directly from the copyright holder. To view a copy of this licence, visit http://creativecommons.org/licenses/by/4.0/.

\section{References}

1. Araguas MA, Herrera A, Garrido I et al (2020) Risk factors for major adverse cardiovascular events after osteoporotic hip fracture repair surgery. Injury 51(Suppl 1):S30-S36. https://doi.org/10. 1016/j.injury.2020.03.052

2. Kanis JA, Oden A, McCloskey EV et al (2012) A systematic review of hip fracture incidence and probability of fracture worldwide. Osteoporos Int 23:2239-2256. https://doi.org/10.1007/ s00198-012-1964-3

3. Smith T, Pelpola K, Ball M et al (2014) Pre-operative indicators for mortality following hip fracture surgery: a systematic review and meta-analysis. Age Ageing 43:464-471. https://doi.org/10. 1093/ageing/afu065

4. von Friesendorff M, McGuigan FE, Wizert A et al (2016) Hip fracture, mortality risk, and cause of death over two decades. Osteoporos Int 27:2945-2953. https://doi.org/10.1007/ s00198-016-3616-5

5. Kaasenbrood L, Boekholdt SM, van der Graaf Y et al (2016) Distribution of estimated 10-year risk of recurrent vascular events and residual risk in a secondary prevention population. Circulation 134:1419-1429. https://doi.org/10.1161/CIRCULATIONAHA. 116.021314

6. Bai YH, Li ZY, Chang DY et al (2018) The BVAS is an independent predictor of cardiovascular events and cardiovascular diseaserelated mortality in patients with ANCA-associated vasculitis: a study of 504 cases in a single Chinese center. Semin Arthritis Rheum 47:524-529. https://doi.org/10.1016/j.semarthrit.2017.07. 004

7. Sazgary L, Puelacher C, Lurati Buse G et al (2020) Incidence of major adverse cardiac events following non-cardiac surgery. Eur Heart J Acute Cardiovasc Care. https://doi.org/10.1093/ehjacc/ zuaa008

8. Cullen MW, Gullerud RE, Larson DR et al (2011) Impact of heart failure on hip fracture outcomes: a population-based study. J Hosp Med 6:507-512. https://doi.org/10.1002/jhm.918

9. Lv H, Zhang L, Long A et al (2016) Red cell distribution width as an independent predictor of long-term mortality in hip fracture 
patients: a prospective cohort study. J Bone Miner Res 31:223233. https://doi.org/10.1002/jbmr.2597

10. Sultana J, Giorgianni F, Rea F et al (2019) All-cause mortality and antipsychotic use among elderly persons with high baseline cardiovascular and cerebrovascular risk: a multi-center retrospective cohort study in Italy. Expert Opin Drug Metab Toxicol 15:179-188. https://doi.org/10.1080/17425255.2019.1561860

11. Guasch-Ferre M, Liu G, Li Y et al (2020) Olive Oil Consumption and Cardiovascular Risk in U.S. Adults J Am Coll Cardiol 75:1729-1739. https://doi.org/10.1016/j.jacc.2020.02.036

12. Khan SS, Ning H, Wilkins JT et al (2018) Association of body mass index with lifetime risk of cardiovascular disease and compression of morbidity. JAMA Cardiol 3:280-287. https://doi.org/ 10.1001/jamacardio.2018.0022

13. Meinberg EG, Agel J, Roberts CS et al (2018) Fracture and dislocation classification compendium-2018. J Orthop Trauma 32(Suppl 1):S1-S170. https://doi.org/10.1097/BOT.0000000000 001063

14. Cher EWL, Allen JC, Howe TS et al (2019) Comorbidity as the dominant predictor of mortality after hip fracture surgeries. Osteoporos Int 30:2477-2483. https://doi.org/10.1007/ s00198-019-05139-8

15. Charlson M, Szatrowski TP, Peterson J et al (1994) Validation of a combined comorbidity index. J Clin Epidemiol 47:1245-1251. https://doi.org/10.1016/0895-4356(94)90129-5

16. Jorgensen ME, Torp-Pedersen C, Gislason GH et al (2014) Time elapsed after ischemic stroke and risk of adverse cardiovascular events and mortality following elective noncardiac surgery. JAMA 312:269-277. https://doi.org/10.1001/jama.2014.8165

17. Menendez ME, Memtsoudis SG, Opperer M et al (2015) A nationwide analysis of risk factors for in-hospital myocardial infarction after total joint arthroplasty. Int Orthop 39:777-786. https://doi. org/10.1007/s00264-014-2502-z

18. D'Agostino RB Sr, Vasan RS, Pencina MJ et al (2008) General cardiovascular risk profile for use in primary care: the Framingham
Heart Study. Circulation 117:743-753. https://doi.org/10.1161/ CIRCULATIONAHA.107.699579

19. Goff DC Jr, Lloyd-Jones DM, Bennett G et al (2014) 2013 ACC/ AHA guideline on the assessment of cardiovascular risk: a report of the American College of Cardiology/American Heart Association Task Force on Practice Guidelines. J Am Coll Cardiol 63:2935-2959. https://doi.org/10.1016/j.jacc.2013.11.005

20. Ushirozako H, Ohishi T, Fujita T et al (2017) Does N-terminal pro-brain type natriuretic peptide predict cardiac complications after hip fracture surgery? Clin Orthop Relat Res 475:1730-1736. https://doi.org/10.1007/s11999-017-5245-5

21. Choi JH, Cho DK, Song YB et al (2010) Preoperative NT-proBNP and CRP predict perioperative major cardiovascular events in noncardiac surgery. Heart 96:56-62. https://doi.org/10.1136/hrt.2009. 181388

22. Sandhu A, Sanders S, Geraci SA (2013) Prognostic value of cardiac troponins in elderly patients with hip fracture-a systematic review. Osteoporos Int 24:1145-1149. https://doi.org/10.1007/ s00198-012-2116-5

23. Kim BS, Kim TH, Oh JH et al (2018) Association between preoperative high sensitive troponin I levels and cardiovascular events after hip fracture surgery in the elderly. J Geriatr Cardiol 15:215$221 \mathrm{https} / / /$ doi.org/10.11909/j.issn.1671-5411.2018.03.002

24. Mosk CA, Mus M, Vroemen JP et al (2017) Dementia and delirium, the outcomes in elderly hip fracture patients. Clin Interv Aging 12:421-430. https://doi.org/10.2147/CIA.S115945

Publisher's note Springer Nature remains neutral with regard to jurisdictional claims in published maps and institutional affiliations. 